DOI: 10.14526/2070-4798-2019-14-4-86-90

\title{
Prospects of sports training simulators use at physical culture lessons with students of special medical "A" group
}

\author{
Anastasiya A. Svetlichkina ${ }^{1}$, Oleg A. Kozlyatnikov', Aleksandr V. Dorontsev' ${ }^{1 *}$, Nina A. \\ Zinchuk ${ }^{2}$ \\ ${ }^{1}$ Astrakhan State Medical University \\ Astrakhan, Russia \\ ORCID: OOOo-ooo1-6337-6935, doronceva@rambler.ru \\ ORCID:0ooo-ooo3-1310-5955, oleg_kozlyatnikov@mail.ru \\ ORCID: OOOo-ooo1-9446-103X, aleksandr.doroncev@.rambler.ru \\ ${ }^{2}$ Astrakhan State University, \\ Astrakhan, Russia \\ ORCID: oooo-ooo1-5837-9912, niva-zichuk@mail.ru
}

\begin{abstract}
In the research works of recent years there is a steady tendency of increasing the number of students, who belong to a special medical "A" group. The presence of polypathia among most students creates several restrictions in using standard physical culture means in the program of health-improving lessons. That is why it is necessary to create the methods of an adequate physical load use and evaluation criteria for the mastering level of skills and abilities to use independently motor activity in accordance with the verified diagnosis. In order to define the effectiveness of physical qualities development we held a complex study of students from special medical "A" group (39 men-18-19 years-old). 19 people were included into the experimental group $\left(\mathrm{n}_{1}=19\right)$, the program of which used sports training simulators. The control group included 20 people $\left(\mathrm{n}_{2}=20\right)$, who went in for physical culture lessons according to a standard program. Materials. The results of medical check-ups, the results of functional tests, protocols of testing the level of physical qualities development. Research methods. Information sources analysis and summarizing, verified diagnoses analysis, physical readiness testing. The methodology of sports training-simulators use approbation was realized on the basis of Astrakhan State Medical University. Statistical handling was realized using standard methods of variation statistics (Statistica 11,0). The validity of differences was estimated according to Student t-test. The differences were valid if $\mathrm{p}<\mathrm{0}, 05$. Correlation analysis was realized using Pearson correlation coefficient. Results. The methodology approbation of sports training simulators use at physical culture lessons in a special medical "A" group (men) showed valid increase of power oriented and speed-power qualities, positive tendency of cardiovascular system reserve capacities increase. Conclusion. It was stated that sports training simulators use at physical culture lessons in a special medical "A" group (men) helps to increase the level of physical qualities development, correct motor load, taking into account the anamnesis. We proved the possibility to use sports training simulators with the set vector of load among students with spine pathology. It prevents traumatic load on vertebral zone.
\end{abstract}

Keywords: special medical “A” group, sports training-simulators, physical qualities development

For citation: Anastasiya A. Svetlichkina, Oleg A. Kozlyatnikov, Aleksandr V. Dorontsev*, Nina A. Zinchuk. Prospects of sports training simulators use at physical culture lessons with students of special medical "A" group. Russian Journal of Physical Education and Sport. 2019; 14(4): 73-76. DOI: 10.14526/2070-47982019-14-4-86-90.

\section{INTRODUCTION}

During recent years there is the tendency of increasing the number of students, who belong to a special medical group [2]. In more than $70 \%$ of cases students from special medical "A" and "B" groups have two or more chronic diseases [3]. According to the results of the research works of some authors, the leading position take cardiovascular system diseases and locomotor apparatus diseases, then go respiratory system and vision organs diseases, special attention is paid to the risk of disadaptive reactions development to physical load in students with cardiovascular pathology as the most dangerous for life $[1,5,6,7,10]$. Special importance gains polypathia among most students of special medical groups $[4,8]$. In the opinion of foreign specialists, the main direction of health improving physical culture is scientific-methodical substantiation of 
the personified motor activity formation by means of physical culture and sport [9,11,12]. In this connection we held a research work concerning sports training simulators use during physical culture lessons in a special medical "A" group.

The aim of the research work is to define the effectiveness of sports training simulators use at physical culture lessons among students of a special medical "A" group, who have chronic polypathia in their anamnesis.

The objective: to estimate the influence of sports training simulators use on physical qualities development and the risk of deadaptive reactions development because of physical load.

\section{MATERIALS AND METHODS}

We examined 39 students (men) at the age of 19 to20, who we included into a special medical "A" group. Physical culture lessons were held in a following way: 4 academic hours a week, two hours of which were dedicated to independent work. In most cases anamnesis had the definite nosological specificity. It in $59 \%$ of cases was vertebral zone pathology in a form of scoliotic bearing, round back, I stage scoliosis and CDA (cardiovascular development abnormalities) -mitral valve prolapse, additional chords of the left ventricle, aortic regurgitation. More than 40\% of respondents had excess weight, 2 students had obesity of the $1^{\text {st }}$ degree, 12 students had myopia of the $1^{\text {st }}$ and the $2^{\text {nd }}$ degree, $8 \%$ of the respondents had digestive tract problems. During the research the experimental group included $19\left(\mathrm{n}_{1}=19\right)$ people and the control group- $20\left(n_{2}=20\right)$ people. Polypathia in the groups and the level of physical readiness didn't have considerable differences. During the research the following things were analyzed: test exercises, bicycle ergometry indices, functional tests, clinic results with the initial verified diagnosis. Physical qualities development of each student was checked at the beginning of the year, after the first term and at the end of the research work. Mathematical handling was realized with the help of Statistica 11.0 USA. For the interconnection analysis of normally distributed features we used parametric correlation Pearson method. The research works were held on the basis of Astrakhan State Medical University in
2018/19.

\section{RESULTS AND DISCUSSION}

During the level of physical readiness determination it was mentioned that the indices of power oriented and speed-power readiness among students were at a low level. The distinctive feature of all students was weak spine and hands muscles development, chin-ups at a high bar fulfillment was $3 \pm 1,7$ repetitions, standing long jump - 1,72 $\pm 0,27$ m., dip ups in a lying position $-17 \pm 4,3$ repetitions, body bending from lying position, arms overhead within 1 minute $-23 \pm 5,2$ repetitions. The use of sports training simulators in the experimental group $\left(\mathrm{n}_{1}=19\right)$ for hands and spine muscles development "T-pull" with the set vector of load and "Gravitron" helped to increase the indices in chin-ups at a high bar from $3 \pm 1,7$ repetitions at the beginning of the research till $6 \pm 1,5$ repetitions $(\mathrm{p}<0,05 ; \mathrm{r}-0,655)$ at the end of the year. The exception was the student with the $1^{\text {st }}$ degree of obesity, who didn't fulfill the exercise at a high bar. Power oriented training simulators use for chest muscles development during the research period had a positive effect in "arms extension in lying position" exercise fulfillment from $13 \pm 4,3$ till $21 \pm 3,2$ repetitions ( $\mathrm{p}<0,05 ; \mathrm{r}-\mathrm{o}, 621)$. Complex training simulators use for abdomen muscles development helped to increase the effectiveness in "body bending from lying position, arms overhead" test from 19 $\pm 5,2$ till $31 \pm 2,0$ repetitions within one minute $(\mathrm{p}<0,05 ; \mathrm{r}-$ 0,505). The intensity of exercises fulfillment was determined according to HR individually at the level till 130 beats/min (compensatory zone) with further statistical handling. It revealed the dynamics of HR fluctuation from $83 \pm 5,3$ at the beginning of the lessons till 118 \pm 7,4 beats/min during the main part, decreasing gradually till $93 \pm 6,5$ beats/min during the final part. Extrapolating the results of the load increase at sports training simulators on power oriented and speed-power indices, we received the following results: converse weight decrease at "Gravitron" training simulator for $50 \pm 10 \%$ from the initial testing helped to increase the number of chinups at a high bar for $10 \pm 2,3 \%(\mathrm{p}<0,05 ; \mathrm{r}-0,427)$. Counterbalance weight decrease for $80 \pm 10 \%$ from the initial indices showed the result increase in 
chin-up for $30 \pm 5,0 \%$. Positive results of speedpower indices development were received during sports training simulators use for lower extremities muscles development. During complex use of the exercises for legs extensors and flexors the indices of standing long-jump increased from 1,75 $\pm 0,25 \mathrm{~m}$ till $1,92 \pm 0,11 \mathrm{~m}(\mathrm{p}<0,05 ; \mathrm{r}-0,425)$. In the methodology of loads variability use at sports training simulators the methods of the average amount of repetitions were used (15-18) with the weight $30-40 \%$ of submaximal indices, the load increase at the training simulators was permitted in case of confident exercises fulfillment with HR in the compensatory zone. It is necessary to underline complete absence of disadaptive reactions of cardiorespiratory system to this methodology of motor load determination. According to the results of study during the academic year it was stated that distinct increase of power oriented indices was after the 5 t month of lessons, considerable speed-power indices increase was registered in 7 months. Moreover, training simulators use and ellipsoids use helped to increase reserve-compensatory indices of cardiorespiratory system. It was demonstrated in working load at bicycle ergometer increase during 5 minutes, taking into account personified results from 10 to $30 \mathrm{~W}$, ( $\mathrm{p}<0,05 ; \mathrm{r}-0,476), \mathrm{HR}-$ till 130 beats/min. In the control group $\left(\mathrm{n}_{2}=20\right)$ the structure of lessons didn't include the exercises at sports training simulators, power oriented and speed-power indices didn't have considerable changes. At the same time, at the end of the academic year students from this group had regulatory-adaptive level of cardiovascular system increase. It was characterized by HR decrease during functional tests organization from $137 \pm 8$, 2 beats/min till $120 \pm 7,7$ beats $/ \mathrm{min}(\mathrm{p}<0,05)$.

\section{CONCLUSION}

Thus, it was stated that sports training simulators use at physical culture lessons in a special medical "A" group (men) helped to increase the level of power oriented and speed-power qualities development. The used methodology of the personified training load planning helped to avoid disadaptive reactions to motor activity development. At the same time, polypathia among students demands special approaches to the lessons structure using sports training simulators. In choosing the intensity of the exercises fulfillment it is necessary to take into account the initial indices of the functional tests and the risk factors of locomotor apparatus trauma.

\section{REFERENCES}

1. Legotkin A.N., Lopatin A.B. Ontogenesis of athletes and physical load. Uspehi sovremennoj nauki I obrazovaniya $=$ Success of modern science and education. 2016; 12(1): 122-125 (In Russ., In Engl.).

2. Linkova N.A. Technology of educational process organization in physical upbringing of students at health-improving department. Vestnik Ural'skogo gosudarstvennogo universiteta putej soobcheniya. 2015; 3(27): 81-86 (In Russ.).

3. Karpov V.Yu., Zavalishina S.Yu., Dorontsev A.V., Skorosov K.K., Ivanov D.A. Physiological basis of physical rehabilitation of athletes after ankle injuries. Indian Journal of Public Health Research and Development. 2019; 10(10): 2723-2728 (In Engl.).

4. Lobanov Yu. Ya., Kovalenko V.N., Mironova O.V., Ustinova O.N. Methodology of training students with a low level of physical readiness. Uchenye zapiski universiteta imeni P.F. Lesgafta. 2018; 2(156): 126-130 (In Russ.).

5. Chichkova M.A., Svetlichkina A.A. Patent 2672934 RF. The way of a complex estimation of cardiovascular system indices among disabled people. URL: https://yandex.ru/patents/doc/ RU2672934C1_20181121.

6. Chichkova M.A., Svetlichkina A.A. Patent 2652968 RF. The way of a complex estimation of cardiovascular system indices among athletes. URL: https://yandex.ru/patents/doc/ RU2652968C1_20180503.

7. Chichkova M.A., Svetlichkina A.A. Patent 2672935 RF. The way of a complex estimation of cardiovascular system indices among people with the restricted auditory capacities. URL:https://yandex. ru/patents/doc/RU2672935C1_2017132798.

8. Chichkova M.A., Svetlichkina A.A., Dorontsev A.V. The estimation of adaptive kinds of sports influence on reserve capacities of cardiovascular system among the patients with neurosensory hearing loss of the I-II degree. Chelovek. Sport. Medicina. 2018; 18(4): 117-122 (In Russ.).

9. Magda SH Afifi. The Role of Quercetin on some Cardio-Vascular Parameters in Rats with Insulin Resistance Syndrome. Research Journal of Pharmaceutical, Biological and Chemical Sciences. 2017; 8(5): 460-469 (In Engl.).

10. Armstrong N., Welsman J.R. The physical activity patterns of European youth with reference to methods of assessment. Sports 
Medicine. 2006; 36: 1067-1086. (In Engl.)

11. Craig C.L., Marshall A.L., Sjostrom

M., Bauman A.E., Booth M.L., Ainsworth B.E., et

al. International physical activity questionnaire: 12-country reliability and validity. Medicine and Sciences in Sports and Exercise. 2003; 35: 13811395 (In Engl.).

12. Esculcas U., Mota J. Physical activity and leisure behaviors in adolescents: The influence of physical activity characteristics and the socioeconomic status. International Journal of Behavioral Medicine. 2000; 7: 208-213 (In Engl.).

13. Gulbe A., Kuznetsova Z.M. Evaluation of performance indicators on the rowing simulator and the result on the water for 14-15-year-old kayakers. Pedagogiko-psihologicheskie I medicobiologicheskie problemy fizicheskoj kul'tury I sporta = Pedagogico-psychological and medicobiological problems of physical culture and sport. 2015; 4(37): 67-72. DOI 10.14526/01_1111_52.

14. Yakupov A.M., Stepanov M.Y. Some aspects of a strike formation in boxing. Pedagogikopsihologicheskie I medico-biologicheskie problemy fizicheskoj kul'tury I sporta = Pedagogicopsychological and medico-biological problems of physical culture and sport. 2014; 9(2): 162-164. DOI 10.14526/oo_1111_22 (In Russ., In Engl.)

\section{Submitted: 13.11.2019}

\section{Author's information:}

Anastasiya A. Svetlichkina - Assistant, Astrakhan State Medical University, 4140oo, Russia, Astrakhan, Bakinskaya str., House 121, e-mail: doronceva@rambler.ru

Oleg A. Kozlyatnikov - Candidate of Pedagogics, Associate Professor, Astrakhan State Medical University, 4140oo, Russia, Astrakhan, Bakinskaya str., House 121, e-mail:oleg kozlyatnikov@mail.ru Aleksandr V. Dorontsev - Candidate of Pedagogics, Associate Professor, Astrakhan State Medical University, 4140oo, Russia, Astrakhan, Bakinskaya str., House 121, e--mail: aleksandr.doroncev@. rambler.ru

Nina A. Zinchuk - Candidate of Pedagogics, Associate Professor, Astrakhan State University, 414063, Russia, Astrakhan, Tatishcheva str., House 20, e-mail:-niva-zichuk@mail.ru 